\title{
Broadband Matching in Simultaneous Information and Power Transfer
}

\author{
Sai Ho Yeung, Tapan Kumar Sarkar, Magdalena Salazar-Palma, Miguel Angel Lagunas and
} Ana Perez-Neira

Abstract-This paper presents the implementation and the effect of broadband matching in simultaneous information and power transfer. The narrowband characteristic of antennas limited the applications of simultaneous information and power transfer. The simplified real frequency technique (SRFT) and the nonfoster matching technique have been presented to improve the performance in terms of channel capacity and power delivery. Electromagnetic simulation and multiobjective optimization are performed to analyze the tradeoff between the channel capacity and power delivery in different matching conditions. The performance gain using the matching networks have been demonstrated and analyzed.

Keywords—Antenna; broadband matching; channel capacity; power transmission

\section{INTRODUCTION}

A ntennas [1] are useful in information transfer [2], [3] as well as power transfer [4] - [6]. In some applications, the two functions should be applied simultaneously [7], [8]. Two practical applications are passive radio frequency identification (RFID) [9], [10] and wireless sensing system (WSN) [11], [12]. The role of information transfer in a RFID system is to detect objects, while its role in a WSN is to monitor the environment. The role of power transfer in both RFID system and WSN is powering or charging the tags used in the systems.

In [7], [8], the tradeoff between the information transfer and power transfer have been analyzed using the Shannon channel capacity [13], Gabor channel capacity [14], and Hartley-Nyquist-Tuller (HNT) channel capacity [15], [16]. An optimization problem is considered to allocate an average power $P_{a v}$ to $M$ frequency channels for transmission such that the channel capacity and power delivery are maximized, formulated as:

$$
\begin{array}{ll}
\text { Maximize } & F_{1}=\text { Channel capacity (bits/s) } \\
\text { Maximize } & F_{2}=\text { Power delivery (W) }
\end{array}
$$

Since the average power available is $P_{a v}$, the power allocation should satisfy the following condition so that the total power allocated equal $P_{a v}$ :

$$
\sum_{m=1}^{M} P_{i}\left(f_{m}\right)=P_{a v}
$$

where $P_{i}\left(f_{m}\right)$ is the power allocated to the frequency channel $f_{m}$, for $m=1,2, \ldots$, M. A set of solutions can be found showing the tradeoff between the channel capacity and power delivery. Some of the solutions have a larger channel 
capacity while the others have a larger power delivery. Those solutions are referred as the non-dominated solution in multi-objective optimization [17].

In the power allocation of information and power transfer in [8], the power efficiency and voltage efficiency of different channels are considered in the power allocation process. However, the voltage standing wave ratios (VSWR) of the channels were not being considered. It becomes a problem when VSWR of the antenna becomes large so that input power to the antenna would reflect back to the generator. The VSWR of the circuit related to the amount of reflected power is shown in Table I. When the VSWR is larger than 6.0, more than half power would be reflected to the generator. It would be dangerous in some transmitter designs if it heat up and damage the signal generator and processor. Also, it is obviously a waste of energy. Therefore, it would be necessary to set a constraint such that the transmitter should not provide any input power to the channel with a large VSWR. However, using fewer channels in transmission would result in a reduction of channel capacity. Therefore, this paper proposes applying a broadband matching circuit in designing the system. By reducing the VSWR at different frequency, more channels can be used without worrying about the reflected power. The implementation of the matching network using a simplified real frequency technique (SRFT) [18] - [22] and a non-foster matching technique [23] - [27] and their effect on the simultaneous information transfer and power transfer would be analyzed in this paper.

This paper is organized as follows: In Section II, the system model and definitions for simultaneous wireless communication and power transfer is considered. In Section III, the method of building the matching network with simplified real frequency technique and the non-foster matching network would be presented. In Section IV, the performance of the system would be compared in the situations with and without the matching network. Finally, the conclusion is given in Section V.

\section{PROBLEM DEFINITIONS}

Same as the situation in [8], a wireless system with transmitting and receiving dipole antennas is considered for simultaneous information and power transfer. The configuration is shown in Fig. 1. The transmitter and receiver are separated by $100 \lambda$, where $\lambda=0.3 \mathrm{~m}$ is the wavelength at $1 \mathrm{GHz}$. The system impedance in this paper is chosen as 50 $\Omega$. The length of the dipole is $140 \mathrm{~mm}$.

The power transfer efficiency $\eta_{P}(f)$ and the voltage transfer efficiency $\eta_{V}(f)$ can be calculated as:

$$
\begin{gathered}
\eta_{P}(f)=\frac{\left|I_{L}(f)^{2} Z_{L}\right|}{\left|V_{i}(f) I_{i}(f)\right| \cos \left[I_{i}(f)-\angle V_{i}(f)\right]} \\
\eta_{V}(f)=\frac{\left|V_{L}(f)\right|}{\left|V_{i}(f)\right|}
\end{gathered}
$$

To calculate the above efficiency, an EM simulation is carried out. With a voltage excitation at the input, the currents on the circuit can then be found. Thus, the frequency response of the power transfer efficiency and voltage transfer efficiency can be obtained. 
With the EM simulation [28], the VSWR of the dipole is shown in Fig. 2 (blue dotted line). The impedance bandwidth defined by VSWR $<3$ and VSWR $<2$ are $0.92-1.09 \mathrm{GHz}$ and $0.95-1.04 \mathrm{GHz}$, respectively. The power transfer efficiency $\eta_{P}(f)$ and the voltage transfer efficiency $\eta_{V}(f)$ of the transmitter are shown in Fig. 3 and Fig. 4 (blue dotted line), respectively.

\section{A. Total Channel Capacity}

The concept of channel capacity which focuses on the theoretical maximum data rate is applied to represent the performance of information transfer in this paper. Three formulations of capacity are considered: Shannon capacity [13], Gabor capacity [14], and Hartley-Nyquist-Tuller (HNT) capacity [15], [16]. The three formations of channel capacity have been applied to analyze the information and power transfer in [8]. Authors are referred to [8] and [29] for the details of channel capacity formulations, However, the following provides a brief introduction.

Shannon capacity considers the maximum data rate in the presence of noise and is derived under the assumption that both the noise as well as the received signal are Gaussian distributed. This is not the case for Gabor and the HNT channel capacity to be presented. When the information is transferred through $M$ channels each with a channel bandwidth $\triangle B$, the Shannon capacity is given by

$$
C_{S}=\sum_{m=1}^{M} \log _{2}\left[1+\frac{\eta_{P}\left(f_{m}\right) P_{i}\left(f_{m}\right)}{P_{N}}\right] \Delta B
$$

, where $P_{i}\left(f_{m}\right)$ and $\eta_{P}\left(f_{m}\right)$ are the input power and the power transfer efficiency at the $m$-th channel, respectively.

Next, Gabor capacity considers the interaction between the signal and the thermal noise. With the step size chosen

to be consistent to the Shannon capacity [14] the Gabor capacity can be represented by $C_{G}=\sum_{m=1}^{M} \log _{2}\left[\frac{1}{2}+\frac{1}{2} \sqrt{1+\frac{4 \eta_{i}\left(f_{m}\right) P_{i}\left(f_{m}\right)}{P_{N}}}\right] \Delta B$

Then, HNT capacity accounts for the signal and noise voltage but not the power, which is given by

$$
C_{H N T}=\sum_{m=1}^{M} 2 \log _{2}\left[1+\frac{\eta_{V}\left(f_{m}\right) V_{i}\left(f_{m}\right)}{V_{N}}\right] \Delta B
$$

where $V_{i}$ and $V_{N}$ represent the signal voltage and noise voltage, respectively. Although the Shannon capacity and Gabor capacity are both calculated based on the noise power $P_{N}$, the HNT capacity is calculated based on the noise voltage $V_{N}$.

In the analysis in this paper, the three capacities will be compared on the same graph. When Shannon capacity and Gabor capacity are evaluated with $P_{N}$, the $V_{N}$ used in HNT capacity would be assigned by

$$
V_{N}=\sqrt{P_{N} Z_{L}}
$$


Although the signal is transmitted using a channel bandwidth of $\Delta B$, the voltages $V_{i}$ and $V_{N}$ here are accounted as if the signal is transmitted with the center frequency. Nevertheless, the equation (8) accounts for the ratio but not the magnitudes of the voltages, so the form of representation does not matter.

\section{B. Power Delivery}

The power that can be regenerated for powering or charging the receivers depends on the structure of the specific RF-DC rectifier circuit in use. The rectifier performance could be frequency dependent and could be nonlinear. This paper would not look into the actual power that can be regenerated from the receiver. Instead, for the ease of analysis the term "power delivery" $P_{d}$ is defined as the following:

$$
\begin{gathered}
P_{d}=\sum_{m=1}^{M} P_{i}\left(f_{m}\right) \eta_{P}\left(f_{m}\right) \\
P_{d}=\sum_{m=1}^{M}\left|\frac{V_{i}\left(f_{m}\right)^{2} n_{V}\left(f_{m}\right)^{2}}{Z_{L}}\right|
\end{gathered}
$$

In the following analysis, an assumption has to be made that the more the power delivery $P_{d}$, the more would be the power regenerated from the receiver. Therefore, the designers should consider the validity of Eqts. (10), (11), and this assumption for their specific rectifier circuits when they work out the same analysis in this paper. However, they can derive an accurate representation of the average regenerated power for their specific RF-DC rectifier circuit, and use them to replace the Eqts. (10) and (11) for a more accurate analysis.

\section{C.Limitation on VSWR}

To demonstrate the tradeoff between the total channel capacity and power delivery, for $M=21$ channels with bandwidth $\Delta B=20 \mathrm{MHz}$, centered at $f_{m}=0.8 \mathrm{GHz}, 0.82 \mathrm{GHz}, \ldots, 1.20 \mathrm{GHz}$ are used in this scenario. The transmission power of $P_{a v}=5 \mathrm{~W}$, and the noise power of $P_{N}=10^{-8} \mathrm{~W}$ or $10^{-7} \mathrm{~W}$ would be used throughout the paper. Since the reflected power may heat up or damage the signal source, it would be preferable to set a constraint on the VSWR such that the transmitter will not provide any input power to the channel with a large VSWR. There is a common practice in microwave engineering to define the impedance bandwidth of VSWR $<3$ or VSWR $<2$, which implies that the reflected power is limited to $25 \%$ and $11 \%$, respectively. Multi-objective optimizations (by genetic algorithm [17], [30]) on the total channel capacity and power delivery (equations 1 and 2) are then performed with the constraint on the impedance bandwidth.

The non-dominated solutions showing the tradeoff between the total Shannon channel capacity and power delivery are shown in Fig. 5. The achievable maximum capacity decreased from $1.67 \mathrm{Gbit} / \mathrm{s}$ to $1.01 \mathrm{Gbit} / \mathrm{s}$ and $0.66 \mathrm{Gbit} / \mathrm{s}$ when the constraints of VSWR $<3$ and VSWR $<2$ are applied, respectively, in the case of $P_{N}=10^{-8} \mathrm{~W}$. The achievable maximum power delivery is the same in all cases, because the maximum power delivery is achieved by the inputting all the power to the one channel with the largest power efficiency. However, it is different out of the maximum region. Considering the same capacity of $1 \mathrm{Gbit} / \mathrm{s}$, the power delivery without VSWR constraint is larger than the power delivery with the constraint of VSWR $<3(4.63 \mu \mathrm{W}$ over $4.48 \mu \mathrm{W})$. The same decrement of 
maximum channel capacity applied when the noise power increased to 10 times $\left(P_{N}=10^{-7} \mathrm{~W}\right)$. In short, the sums of the capacity formulas are performed only for those frequencies where the VSWR is below the given mark.

\section{MATCHING NETWORK}

From the last section, it is shown that the narrowband characteristic of the dipole antenna limited the channel capacity when the channels with large VSWR are given up. This section will introduce the use of a matching network to improve the VSWR of the circuitry.

\section{A. Simplified real frequency technique (SRFT)}

This section introduces the use of the SRFT [18] - [22] to build a broadband matching network. SRFT is a robust approach which can match antennas [19 - 21] as well as active amplifier circuits [22]. This method assumes the matching network is lossless and the scattering parameters are given by the Belevitch representation [31]:

$$
\begin{aligned}
& S_{11}(s)=\frac{h(s)}{g(s)}=\frac{h_{0}+h_{1} s+\ldots+h_{n} s^{n}}{g_{0}+g_{1} s+\ldots+g_{n} s^{n}} \\
& S_{21}(s)=S_{12}(s)= \pm \frac{s^{k}}{g(s)} \\
& S_{22}(s)=-(-1)^{k} \frac{h(-s)}{g(s)}
\end{aligned}
$$

where $n$ is the number of reactive elements in the matching network and $k$ is the integer specifying the order of the zero of transmission at the origin.

The flowchart of SRFT is shown in Fig. 6 which includes an optimization loop driven by least square methods. At the start of the algorithm, it initializes the coefficients of $h(s)$, where typical initial values can be chosen in the range of $h_{i}=[-1,1]$. After that, it goes into an optimization loop. In each iteration, firstly the coefficients of $g(s) g(-s)$ are computed by:

$$
g(s) g(-s)=h(s) h(-s)+(-1)^{k} s^{2 k}=G_{0}+G_{1} s^{2}+\ldots+G_{n} s^{2 n}
$$

, where

$$
\begin{aligned}
& G_{0}=h_{0}^{2} \\
& G_{1}=-h_{1}^{2}+2 h_{2} h_{0}
\end{aligned}
$$




$$
G_{i}=(-1)^{i} h_{i}^{2}+2\left[2 h_{2 i} h_{0}+\sum_{j=2}^{i}(-1)^{j-1} h_{j-1} h_{2 i-j+1}\right]
$$

$G_{k}=\left.G_{i}\right|_{i=k}+(-1)^{k}$

$G_{n}=(-1)^{n} h_{n}^{2}$

Then, by computing the left half plane roots of $g(s) g(-s)$, the polynomial $g(\mathrm{~s})$ can be formed. Next, the transducer power gain $T(\omega)$ of the network is calculated by:

$$
T(\omega)=\frac{\left[1-\left.\Gamma_{S}(\omega)\right|^{2}\right]\left[1-\left|\Gamma_{L}(\omega)\right|^{2}\right]\left|\omega^{2 k}\right|}{\left|g(j \omega)-\Gamma_{S}(\omega) h(j \omega)-(-1)^{k} \Gamma_{S}(\omega) \Gamma_{L}(\omega) g(-j \omega)+(-1)^{k} \Gamma_{L}(\omega) h(-j \omega)\right|^{2}}
$$

, where

$\Gamma_{S}(\omega)=\frac{Z_{S}(\omega)-R_{0}}{Z_{S}(\omega)+R_{0}} \quad \Gamma_{L}(\omega)=\frac{Z_{L}(\omega)-R_{0}}{Z_{L}(\omega)+R_{0}}$

and $R_{0}$ is the normalizing resistance of the S-parameters $\left(R_{0}=50 \Omega\right.$ is considered in this paper). $Z_{S}(\omega)$ and $Z_{L}(\omega)$ are the impedance of the source and the load connecting to the matching network, respectively.

Finally, at the end of the iteration, the error function $\delta$ is computed by:

$$
\delta=\sum_{i=1}^{m}\left[\frac{T\left(\omega_{i}\right)}{T_{0}\left(\omega_{i}\right)}-1\right]^{2}
$$

where $\omega_{1}, \omega_{2}, \ldots, \omega_{m}$ are the $m$ frequency points of interest, and $T\left(\omega_{i}\right)$ and $T_{0}\left(\omega_{i}\right)$ are the transducer power gain and the desired gain at $\omega_{i}$, respectively. This error function $\delta$ is to be minimized in this least squares optimization loop.

Then, it checks against the termination condition of the least squares algorithm. If it continues the next iteration, the coefficients of $h(s)$ are updated according to the least squares algorithm to minimize $\delta$. By continuing the iteration, the transducer power gain $T\left(\omega_{i}\right)$ is converging to the desired gain $T_{0}\left(\omega_{i}\right)$.

After the least squares optimization, the input impedance $Z(\mathrm{~s})$ of the matching network is calculated in the case when the load is perfectly matched $\left(Z_{L}=50 \Omega\right)$ :

$$
Z(s)=50 \frac{1+S_{11}(s)}{1-S_{11}(s)}
$$


Finally, the input impedance of an equivalent matching network with lumped capacitors and inductors element is formulated. By comparing the coefficients of the equation (18) and the real circuit, the values of the inductors and the capacitors in the real matching network can be found.

Now this method is applied to match the dipole which is previously considered in Section II using the least squares optimization provided in MATLAB function lsqnonlin (Solves non-linear least squares problems) [32]. The parameters are chosen as $n=4$ and $k=0$, so that the design is a $n=4$ elements low pass ladder which gives good performance in antenna matching [19]. A typical desired gain can be chosen as $T_{0}\left(\omega_{i}\right) \sim 0.95$ between 0.9 to 1.0 for good broadband performance.

According to [19], a shunt inductor $L_{p}$ should be firstly connected to the load before designed the matching network to give good performance, so the load impedance $Z_{L}(\omega)$ used in equation (16) is given by $Z_{L}(\omega)=\frac{j \omega L_{p} Z_{A}(\omega)}{j \omega L_{p}+Z_{A}(\omega)}$

, where $Z_{A}(\omega)$ is the input impedance of the dipole which can be obtained by electromagnetic simulation [28]. The value of $L_{p}$ is calculated by resonating this element to the input impedance of the dipole antenna at the lower passband edge.

After obtaining the optimized $Z(s)$, the coefficients of the input impedance a matching network consisting of two series connected inductors $L_{1}$ and $L_{2}$ and two shunt connected capacitor $C_{1}$ and $C_{2}$ are compared with $Z(s)$ to obtain the circuit values. The value of $C_{2}$ is too small and so it is taken away from the circuit. Finally, the matching circuit is given in Fig. 7, where $L_{P}=18.2 \mathrm{nH}, L_{1}=14.3 \mathrm{nH}, L_{2}=6.44 \mathrm{nH}$, and $C_{1}=2.49 \mathrm{pF}$.

The VSWR of the dipole with the broadband matching network is given in Fig. 2 (black solid line). The impedance bandwidth defined by VSWR $<3$ and VSWR $<2$ are $0.84-1.14 \mathrm{GHz}$ and $0.88-1.11 \mathrm{GHz}$, respectively. The impedance bandwidth is greatly improved compared with the case of without matching network. The power transfer efficiency $\eta_{P}(f)$ and the voltage transfer efficiency $\eta_{V}(f)$ of the transmitter are shown in Fig. 3 and Fig. 4 (black solid line), respectively. Although the impedance bandwidth has been improved, the power efficiency is not better than the case of without impedance matching. Nevertheless, the objective of reducing the reflected power and improve the impedance bandwidth has been achieved.

\section{B. Non-Foster matching}

The idea of non-foster matching [23] - [27] is to use negative capacitance and negative inductance to cancel the internal capacitance and inductance of an antenna [23]. Hence, the input reactance can be minimized over broadband. The negative capacitance and reactance can be realized by negative impedance converters (NICs) or negative impedance inverters (NIIs or NIVs) [23]. This approach is widely applied to extend the impedance bandwidth of dipoles antennas [23], VHF monopole antennas [24], and microstrip antennas [25], [26].

The non-foster matching circuit used in this paper is shown as Fig. 8 , where $L_{n}=53.9 \mathrm{nH}, C_{n}=0.48 \mathrm{pF}$. Since there are only two elements, the circuit values can be easily obtained by optimization. The VSWR of the dipole with the non-foster matching network is given in Fig. 2 (red dotted line). The impedance bandwidth defined by VSWR $<3$ 
and VSWR $<2$ are $0.70-1.20 \mathrm{GHz}$ and $0.76-1.11 \mathrm{GHz}$, respectively. The impedance bandwidth is significantly larger with the case of without matching network as well as the case of broadband matching using the SRFT technique.

The power transfer efficiency $\eta_{P}(f)$ and the voltage transfer efficiency $\eta_{V}(f)$ of the transmitter are shown in Fig. 3 and Fig. 4 (red dotted line), respectively. The power efficiency and voltage efficiency are both better than the case of without matching network and the case of broadband matching using the SRFT technique.

\section{PERFORMANCE GAIN WITH THE MATCHING NETWORK}

In this section, the performance of simultaneously information and power transfer is evaluated through the three circuit matching conditions: (i) without matching, (ii) broadband matching using the SRFT, and (iii) non-foster matching. The settings of the communication scenario and the constraint on the VSWR used in this section are the same as that described in Section IIC. The performances concerning different constraints on VSWR are presented in the following sub-sections. The frequency range in use for different circuit matching conditions in the presence of VSWR constraint is tabulated in Table II.

\section{Constraint of VSWR $<2$}

When the constraint on VSWR is smaller than 2 in the power allocation, the non-dominated solutions showing the tradeoff between the total Shannon, Gabor, and HNT channel capacity versus power delivery are shown in Fig. 9, Fig. 10, and Fig. 11, respectively.

The achievable maximum Shannon capacity increased from $0.66 \mathrm{Gbit} / \mathrm{s}$ to $1.22 \mathrm{Gbit} / \mathrm{s}$ and $1.57 \mathrm{Gbit} / \mathrm{s}$ when the SRFT broadband matching and the non-foster matching are applied, respectively, in the case of $P_{N}=10^{-8} \mathrm{~W}$. The achievable maximum power delivery is slightly better than the other two matching condition, because it has larger maximum power efficiency across the frequency axis as previously shown in Fig. $3\left(9.85 \times 10^{-7}\right.$ over $\left.9.54 \times 10^{-7}\right)$. It should be noticed that the maximum power delivery is achieved by the inputting all the power to the one channel with the largest power efficiency.

Although the achievable maximum power delivery only differs by a little, the different would be larger out of the maximum region. Considering the same Shannon capacity of $1.21 \mathrm{Gbit} / \mathrm{s}$, the power delivery with non-foster matching network is larger than the power delivery with SRFT broadband matching ( $4.89 \mu \mathrm{W}$ over $4.00 \mu \mathrm{W})$.

The same conclusions from the above observations can be applied when the noise power increased to 10 times $\left(P_{N}\right.$ $\left.=10^{-7} \mathrm{~W}\right)$. Also, observing Fig, 10 and Fig. 11, it is found that the same conclusions also apply to Gabor capacity and HNT capacity.

It is interesting to notice that the achievable maximum Shannon capacity with non-foster matching when $P_{N}=10^{-7}$ $\mathrm{W}$ is about the same as that of without any matching when the noise is ten times smaller $P_{N}=10^{-8} \mathrm{~W}(0.63 \mathrm{Gbit} / \mathrm{s}$ and $0.65 \mathrm{Gbit} / \mathrm{s})$.

\section{Constraint of VSWR $<3$}

When the constraint on VSWR is smaller than 3 in the power allocation, the non-dominated solutions showing the tradeoff between the total Shannon, Gabor, and HNT channel capacity versus power delivery are shown in Fig. 12, Fig. 13, and Fig. 14, respectively. 
Comparing the case with the constraint of VSWR $<2$, now the different between the three matching conditions becomes smaller. The achievable maximum Shannon capacity increased from $1.01 \mathrm{Gbit} / \mathrm{s}$ to $1.42 \mathrm{Gbit} / \mathrm{s}$ and 1.87 $\mathrm{Gbit} / \mathrm{s}$ when the SRFT broadband matching and the non-foster matching are applied, respectively, in the case of $P_{N}=$ $10^{-8} \mathrm{~W}$. Again, the achievable maximum power delivery is slightly better than the other two matching condition (4.92 $\mu \mathrm{W}$ over $4.77 \mu \mathrm{W}$ ), and the different becomes larger out of the maximum region. Considering the same Shannon capacity of $1.42 \mathrm{Gbit} / \mathrm{s}$, the power delivery with non-foster matching network is larger than the power delivery with SRFT broadband matching $(4.86 \mu \mathrm{W}$ over $3.65 \mu \mathrm{W})$.

Again, the same conclusions from the above observations can be applied when the noise power increased to 10 times $\left(P_{N}=10^{-7} \mathrm{~W}\right)$, or using the Gabor capacity or HNT capacity instead of Shannon capacity.

It is interesting to notice that the achievable maximum HNT capacity with non-foster matching when $P_{N}=10^{-7} \mathrm{~W}$ is slightly larger than that of without any matching when the noise is ten times smaller $P_{N}=10^{-8} \mathrm{~W}(1.09 \mathrm{Gbit} / \mathrm{s}$ over $1.08 \mathrm{Gbit} / \mathrm{s})$.

\section{E. Without VSWR constraint}

When there is no VSWR constraint on the power allocation, the non-dominated solutions showing the tradeoff between the total Shannon, Gabor, and HNT channel capacity versus power delivery are shown in Fig. 15, Fig. 16, and Fig. 17, respectively.

Comparing the case with the constraints of VSWR, now the different between the three matching conditions becomes much smaller. It should be noticed that the maximum Shannon capacity decreased from $1.68 \mathrm{Gbit} / \mathrm{s}$ to 1.56 Gbit/s when the SRFT broadband matching is applied in the case of $P_{N}=10^{-8} \mathrm{~W}$, which is because the power efficiency does not improve with the SRFT broadband matching by observing Fig. 3.

However, there are improvements with the non-foster matching. The achievable maximum Shannon capacity increased from $1.68 \mathrm{Gbit} / \mathrm{s}$ to $1.87 \mathrm{Gbit} / \mathrm{s}$ when the non-foster matching is applied in the case of $P_{N}=10^{-8} \mathrm{~W}$. Again, the achievable maximum power delivery is slightly better than the other two matching condition $(4.92 \mu \mathrm{W}$ over 4.77 $\mu \mathrm{W}$ ), and the different becomes larger out of the maximum region. Considering the same Shannon capacity of 1.68 Gbit/s, the power delivery with non-foster matching network is larger than the power delivery without any matching $(4.79 \mu \mathrm{W}$ over $3.44 \mu \mathrm{W})$.

Again, the same conclusions from the above observations can be applied when the noise power increased to 10 times $\left(P_{N}=10^{-7} \mathrm{~W}\right)$, or using the Gabor capacity or HNT capacity instead of Shannon capacity.

\section{CONCLUSION}

The reasons, the implementation, and the results of broadband matching in simultaneously information and power transfer have been presented. Electromagnetic simulation has been performed to calculate the power efficiency and voltage efficiency for power allocation in utilizing a number of frequency channels. It has been demonstrated that the narrow bandwidth of the antenna would limit the performance in information and power transfer. Two methods for broadband matching have been proposed and presented: SRFT and non-foster matching. From the analysis, it is demonstrated that the non-foster matching perform the best, which can improve the performance in terms of channel capacity and power delivery. However, the drawbacks of non-foster matching are the inclusion of negative impedance converters or negative impedance inverters which would increase the complexity of the circuit as well as 
power consumption. The broadband matching a relatively simple approach only includes some lumped components which can also be implemented by microstrip line [19].

\section{REFERENCES}

[1]J. D. Kraus and R. J. Marhefka, Antennas: For All Applications, McGraw-Hill, New York, 2003.

[2]A. Willig, "Recent and emerging topics in wireless industrial communications: A selection," IEEE Trans. Ind. Informat., vol. 4, no. 2, pp. 102-124, May 2008.

[3]M. Jonsson and K. Kunert, "Towards reliable wireless industrial communication with real-time guarantees," IEEE Trans. Ind. Informat., vol. 5, no. 4, pp. 429-442, Nov. 2009.

[4] W. C. Brown, "The History of Power Transmission by Radio Waves", IEEE Transactions on Microwave Theory and Techniques, vol. 32, no. 9, pp. 1230 - 1242, Sept. 1984.

[5]J. A. G. Akkermans, M. C. van Beurden, G. J. N. Doodeeman, and H. J. Visser, "Analytical Models for Low-Power Rectenna Design,” IEEE Antennas and Wireless propagation Letters, vol. 4, pp. 187 - 190, 2005.

[6]C. -C. Lo, Y. -L. Yang, C. -L. Tsai, C. -S. Lee, and C. -L. Yang, "Novel wireless impulsive power transmission to enhance the conversion efficiency for low input power," in Proceedings of the IEEE MTT-S International Microwave Workshop Series on Innovative Wireless Power Transmission: Technologies, Systems, and Applications (IMWS), 2011, pp. $55-58$.

[7]P. Grover, and A. Sahai, "Shannon meets Tesla: Wireless information and power transfer," in Proceedings of the IEEE International Symposium on Information Theory (ISIT), 13-18 June, 2010, pp. 2363 - 2367.

${ }^{[8]}$ E. P. Caspers, S. H. Yeung, T. K. Sarkar, M. S. Palma, M. A. Lagunas, and A. Perez-Neira, "Analysis of Information and Power Transfer in Wireless Communications", IEEE Antenna and Propagation Magazine, submitted and revised.

[9]A. Ashry, K. Sharaf, and M. Ibrahim, "A Simple and Accurate Model for RFID Rectifier," IEEE Systems Journal, vol. 2, no. 4, Dec. 2008.

[10] Y. Yao, J. Wu, Y. Shi, and F. F. Dai, “A Fully Integrated 900-MHz Passive RFID Transponder Front End With Novel Zero-Threshold RF-DC Rectifier," IEEE Transactions on Industrial Electronics, vol. 56, no. 7, pp. 2317 2325, July 2009.

[11] K. M. Farinholt, G. Park, and C. R. Farrar, "RF energy transmission for a low-power wireless impedance sensor node”, IEEE Sens. J., vol. 9, no. 7, pp. 793-800, 2009.

[12] F. Kocer, and M. P. Flynn, “An RF-Powered, Wireless CMOS Temperature Sensor," IEEE Sensors Journal, vol. 6, no. 3, pp. 557 - 564, June 2006.

[13] C. E. Shannon, "Communication in the Presence of Noise," Proceedings of the IRE, vol. 37, no. 1, January 1949, pp. 10-21.

[14] L. Brillouin, Science and Information Theory, New York, Academic Press, 1956.

[15] W. G. Tuller, "Theoretical Limitations on the Rate of Transmission of Information," Proc. of the IRE, vol. 37, no. 5, May 1949, pp. 468-478.

[16] W. G. Tuller, "Information Theory Applied to System Design," Transactions of AIEE, Vol. 69, 1950, pp. 16121614. 
[17] K. Deb, Multi-Objective Optimization Using Evolutionary Algorithms. Chichester, U.K.: Wiley, 2001.

[18] H. J. Carlin, and B. S. Yarman, "The double matching problem: analytic and real frequency solutions" IEEE Trans. Circuits Syst., vol. 28, no. 1, pp. 15-28, Jan. 1983.

[19] H. An, B. K. J. C. Nauwelaers, and A. R. Van de Capelle, "Broadband Microstrip Antenna Design with the Simplified Real Frequency Technique," IEEE Transactions on Antennas and Propagation, vol. 42, no. 2, pp. 129 136, Feb. 1994.

[20] H. An, B. Nauwelaers, and A. Van de Capelle, "Matching network design of microstrip antenna with the simplified real frequency technique," Electron. Lett., vol. 27, no. 24, pp. 2295-2297, Nov., 1991.

[21] K. Yegin and A. Q. Martin, "On the Design of Broad-Band Loaded Wire Antennas Using the Simplified Real Frequency Technique and a Genetic Algorithm," IEEE Transactions on Antennas and Propagation, vol. 51, no. 2, pp. 220 - 228, Feb. 2003.

[22] B. S. Yarman, and H. J. Carlin, "A simplified "real frequency" technique applied to broad-band multistage microwave amplifiers," IEEE Trans. Microwave Theory Tech., vol. 30, no. 12, pp. 2216-2222, Dec. 1982.

[23] S. E. Sussman-Fort, and R. M. Rudish," Non-Foster Impedance Matching of Electrically-Small Antennas," IEEE Transactions on Antennas and Propagation, vol. 57, no. 8, pp. 2230 - 2241, Aug. 2009.

[24] C. R. White, J. S. Colburn, and R. G. Nagele, "A Non-Foster VHF Monopole Antenna," IEEE Antennas and Wireless Propagation Letters, vol. 11, pp. 584 - 587, 2012.

[25] S. Koulouridis, "Non-Foster Design for Antennas," in Proceedings of the IEEE International Symposium on Antennas and Propagation (APSURSI), 2011, pp. 1954 - 1956.

[26] S. Koulouridis, and S. Stefanopoulos, "A Novel Non-Foster Broadband Patch Antenna," in Proceedings of the 6th European Conference on Antennas and Propagation (EUCAP), 2012, pp. 120 - 122.

[27] J. T. Aberle, "Two-Port Representation of an Antenna With Application to Non-Foster Matching Networks," IEEE Transactions on Antennas and Propagation, vol. 56, no. 5, pp. 1218 - 1222, May 2008.

[28] Y. Zhang, T. K. Sarkar, X. Zhao, D. Garcia Doñoro, W.Zhao, M. Salazar-Palma, and S. Ting, Higher Order Basis Based Integral Equation Solver (HOBBIES), John Wiley and Sons, Piscataway, NJ, 2012.

[29] T. K. Sarkar, S. Burintramart, N. Yilmazerl, Y. Zhang, A. De, M. Salazar-Palma, M. A. Lagunas, E. L. Mokole, and M. C. Wicks, "A Look at the Concept of Channel capacity from a Maxwellian Viewpoint," IEEE Antennas and Propagation Magazine, Vol. 50, No. 3, pp. 21 - 50, June 2008.

[30] K. Deb, A. Pratap, S. Agrawal, and T. Meyarivan, "A fast and elitist ultiobjective genetic algorithm: NSGA-II," IEEE Trans. Evol. Comput., vol. 6, pp. 182-197, Apr. 2002.

[31] V. Belevitch, "Elementary application of the scattering formalism to network design," IRE Trans. Circuit Theory, vol. 3, June 1956.

[32] MATLAB is a Trademark of MathWorks, Inc.. 
TABLE I

THE RELATIONSHIP BETWEEN VSWR AND THE REFLECTED POWER

\begin{tabular}{|c|c|c|}
\hline VSWR & $\begin{array}{c}\text { Reflected } \\
\text { Power } \\
\text { (\%) }\end{array}$ & $\begin{array}{c}\text { Reflected } \\
\text { Power } \\
\text { (dB) }\end{array}$ \\
\hline 1.0 & 0.0 & $-\infty$ \\
\hline 1.5 & 4.0 & -14.00 \\
\hline 2.0 & 11.1 & -9.55 \\
\hline 3.0 & 25.0 & -6.00 \\
\hline 4.0 & 36.0 & -4.44 \\
\hline 5.0 & 44.0 & -6.02 \\
\hline 6.0 & 51.0 & -2.92 \\
\hline 7.0 & 56.3 & -2.50 \\
\hline 8.0 & 60.5 & -2.18 \\
\hline 9.0 & 64.0 & -1.94 \\
\hline 10.0 & 66.9 & -1.74 \\
\hline 20.0 & 81.9 & -0.87 \\
\hline 50.0 & 92.3 & -0.35 \\
\hline
\end{tabular}


Fig. 1. Antenna configuration considered for simultaneous information and power transfer.

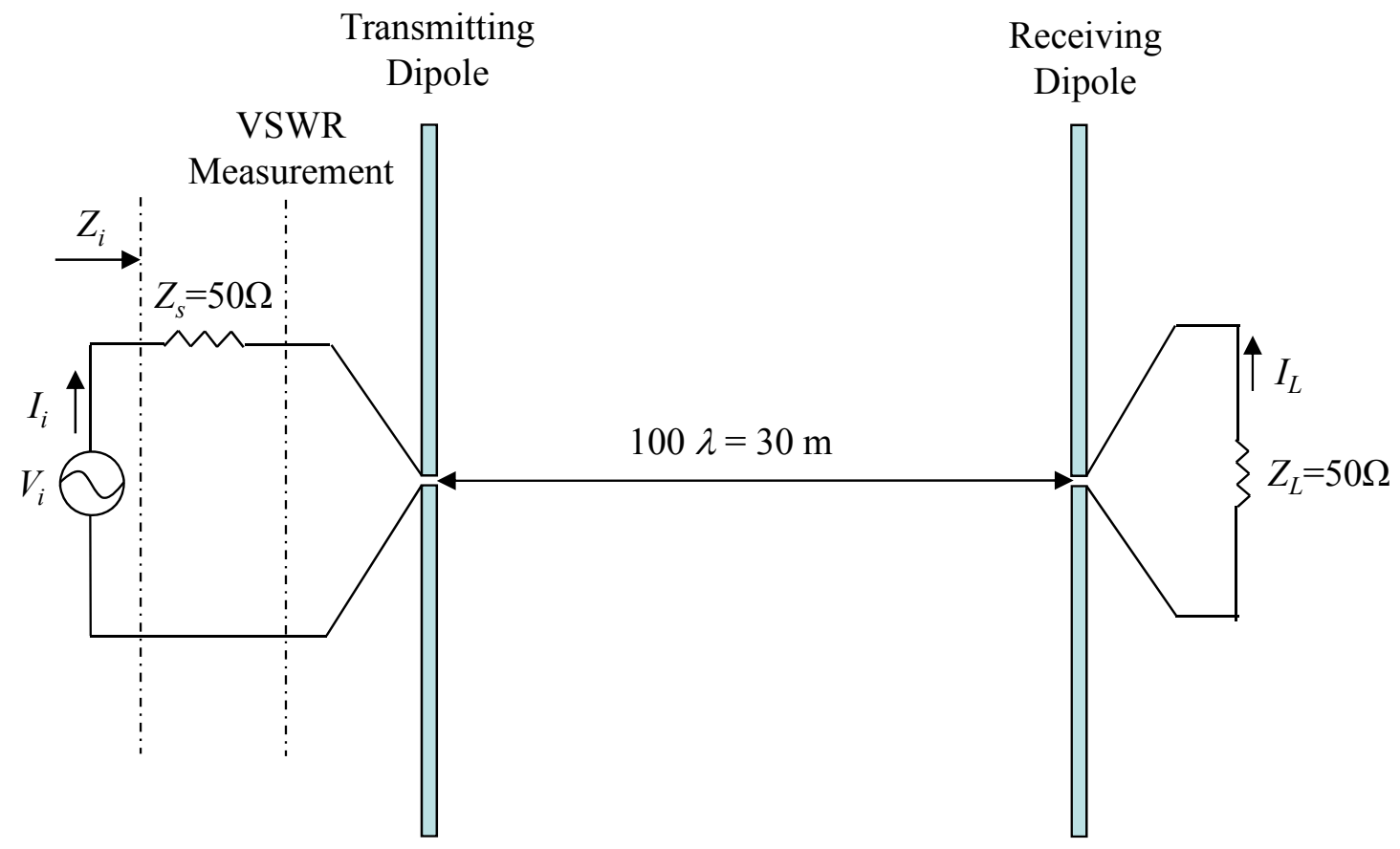


Fig. 2. VSWR of the dipole antenna with different matching schemes.

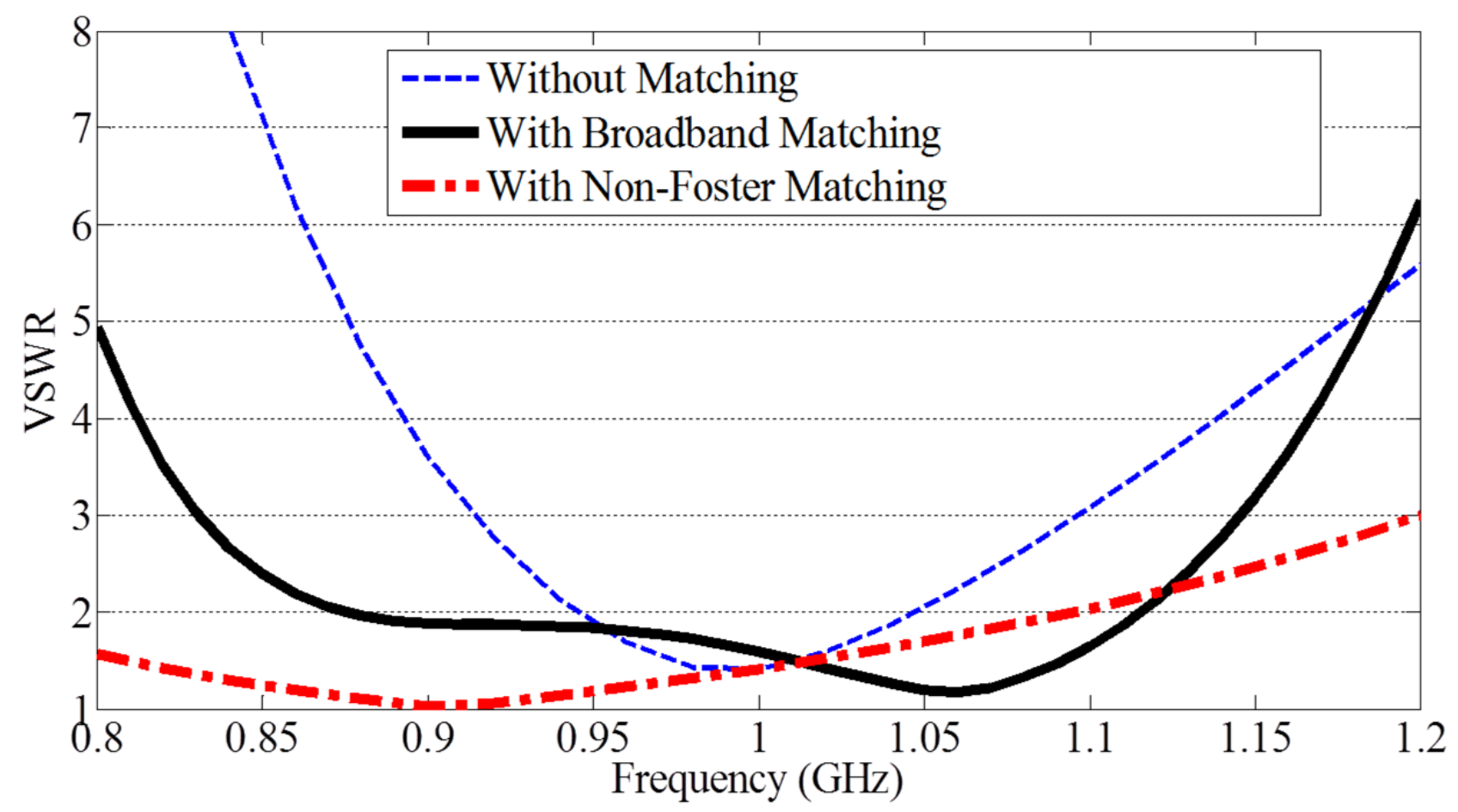


Fig. 3. Power efficiency of the dipole antenna with different matching schemes.

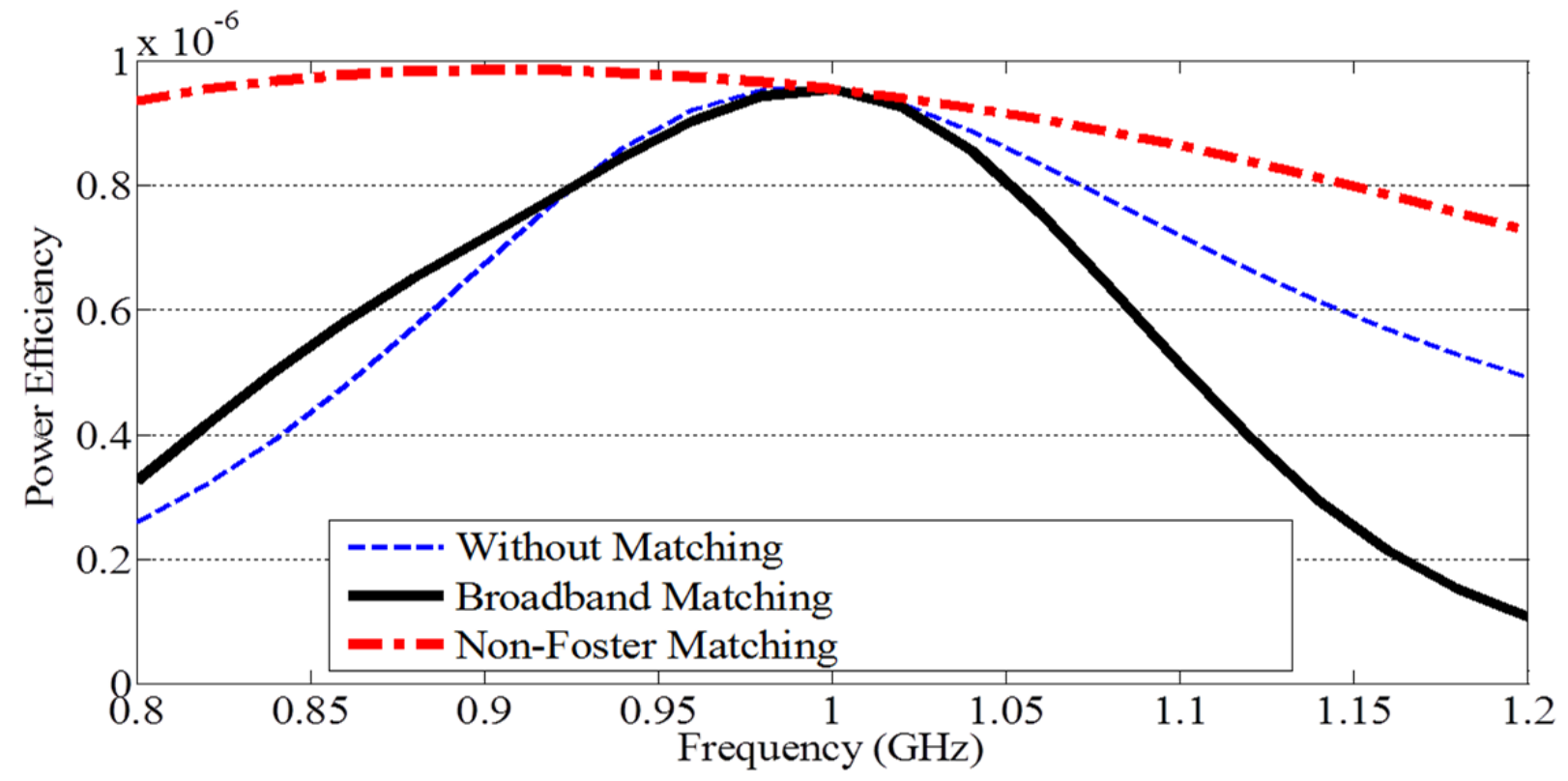


Fig. 4. Voltage efficiency of the dipole antenna with different matching schemes.

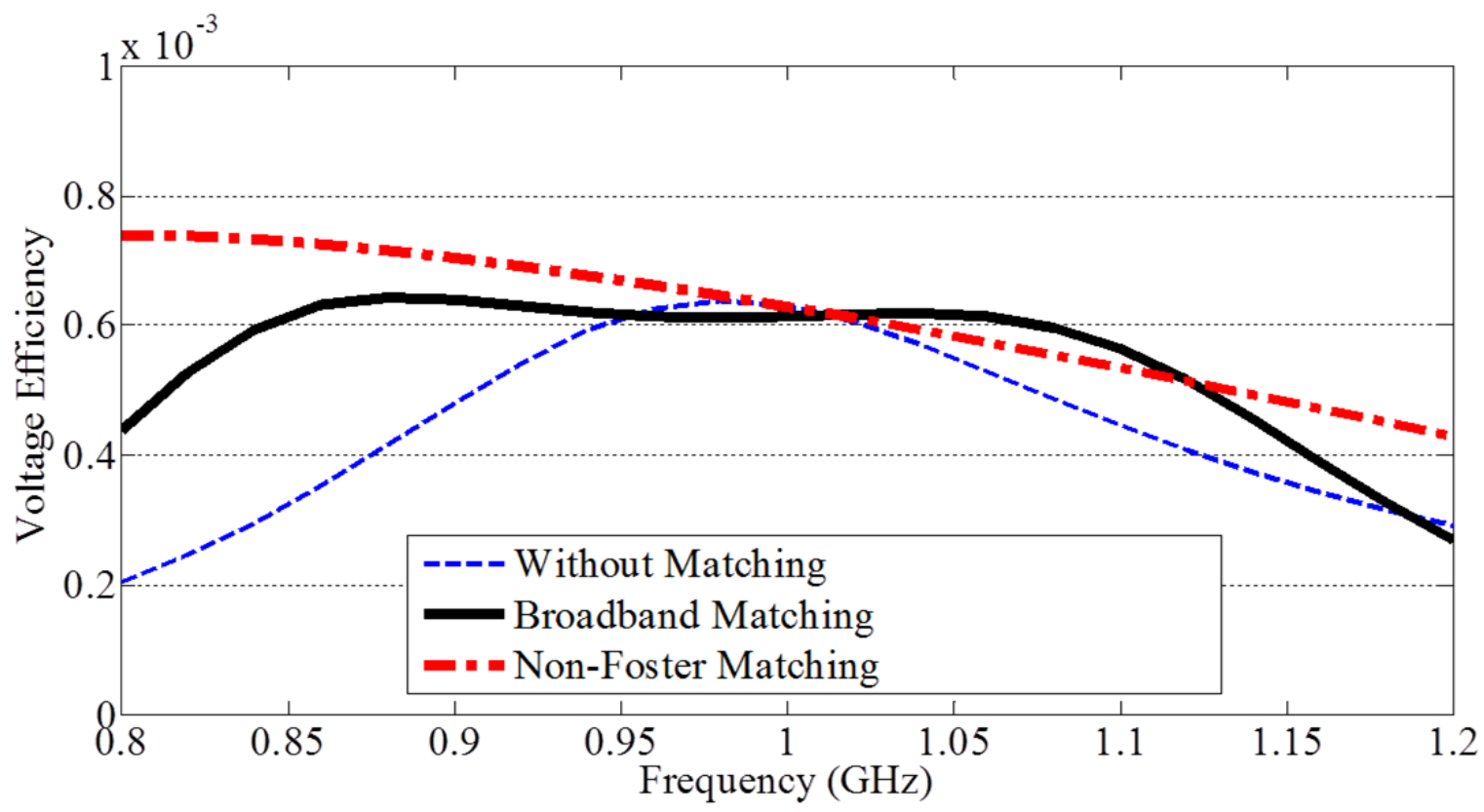


Fig. 5. Shannon capacity versus power delivery in the case without any impedance matching.

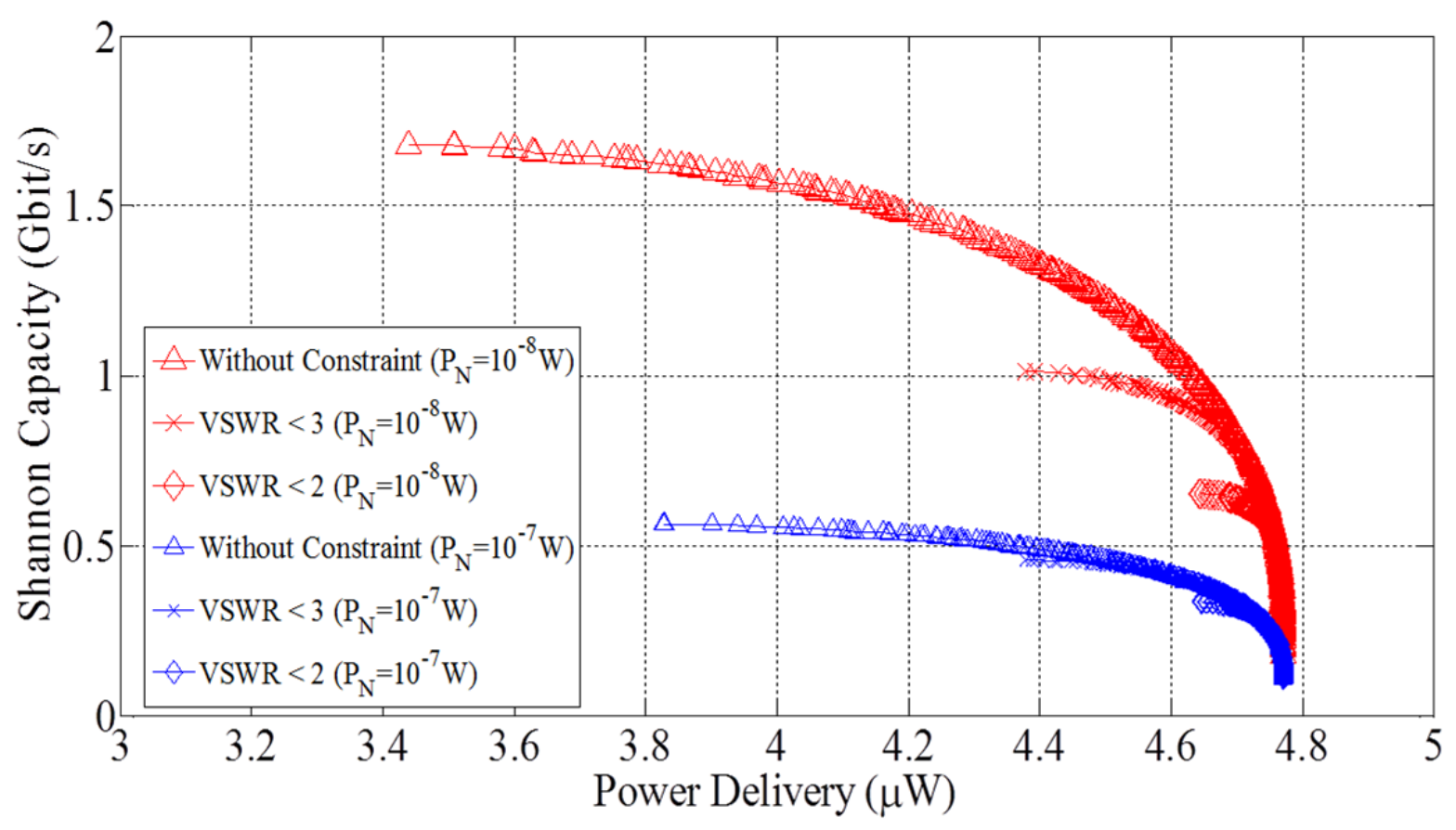


Fig. 6. Flowchart of SRFT for broadband matching.

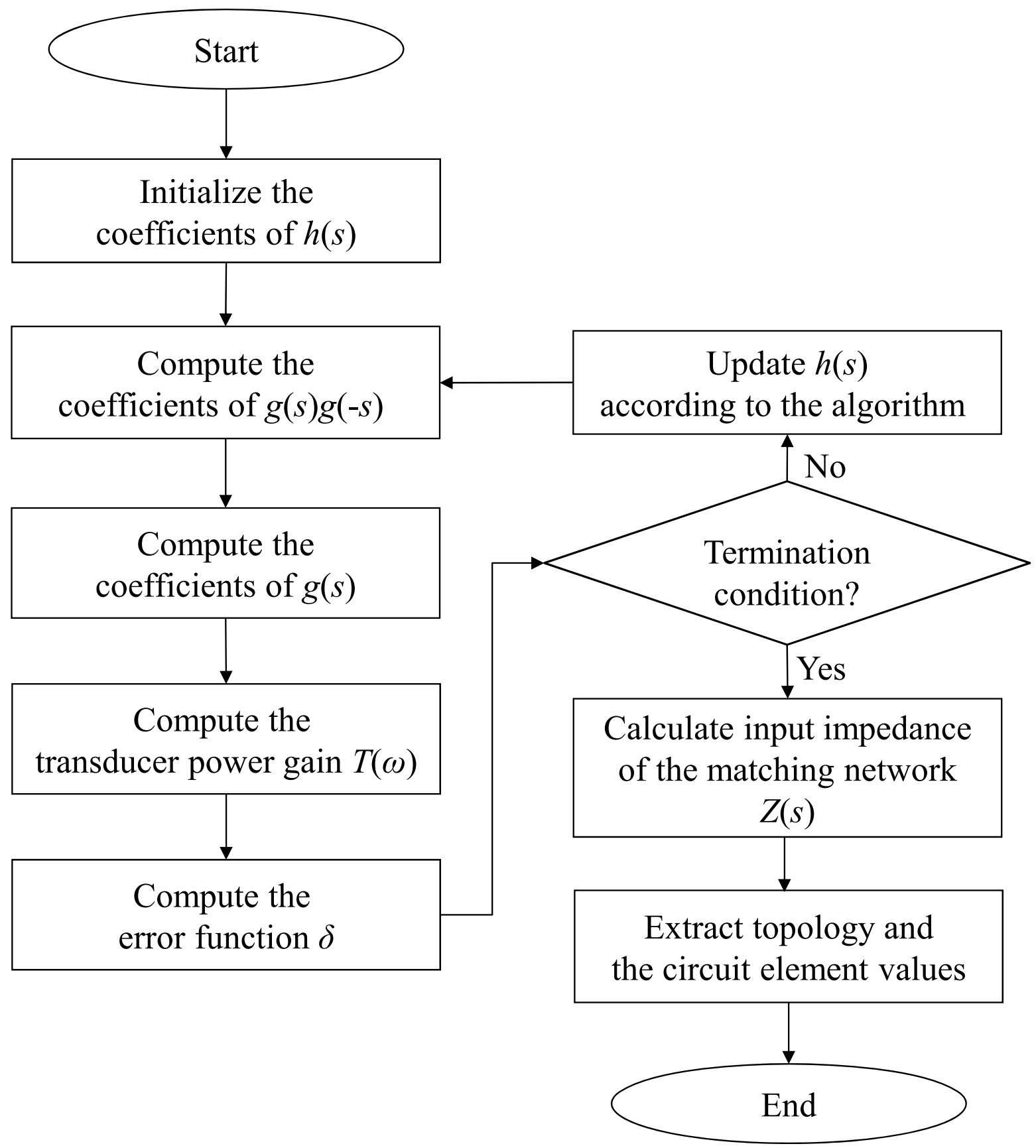


Fig. 7. Matching network designed with SRFT.

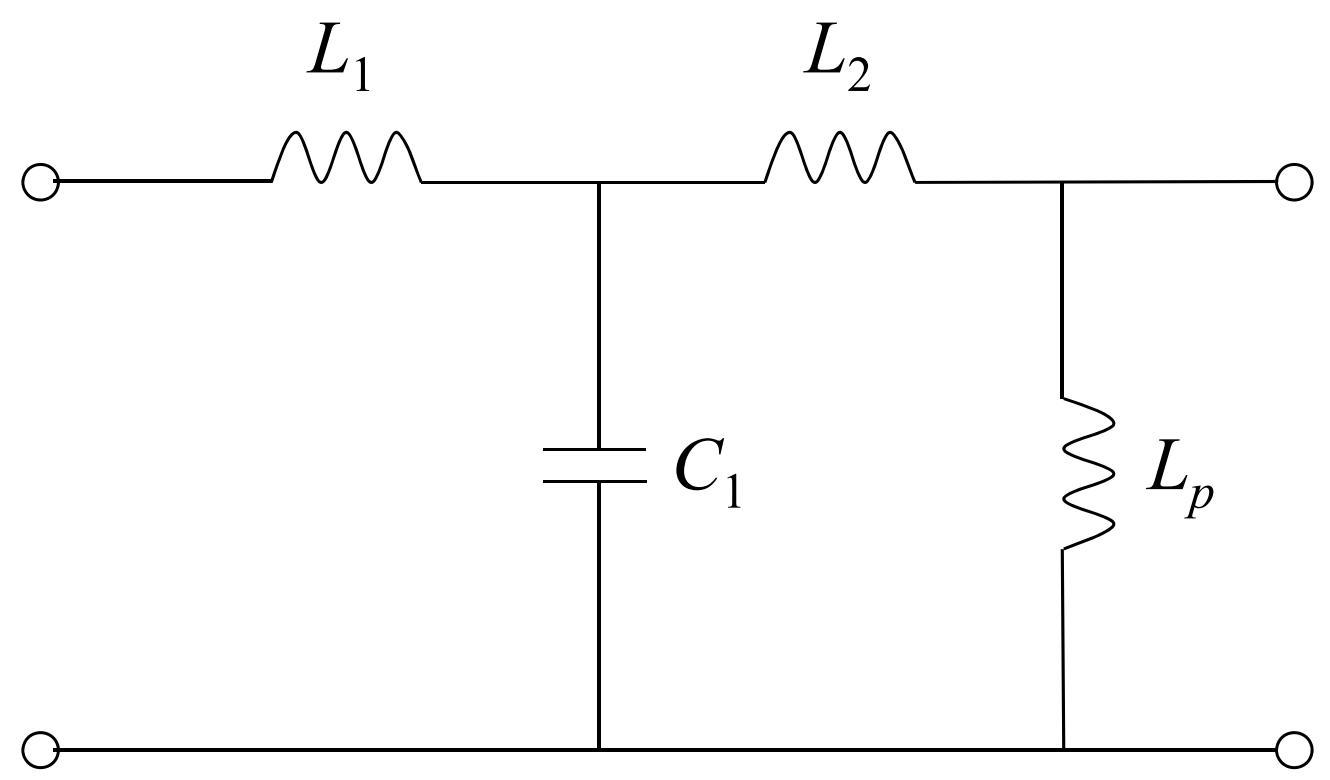


Fig. 8. Non-Foster matching network.
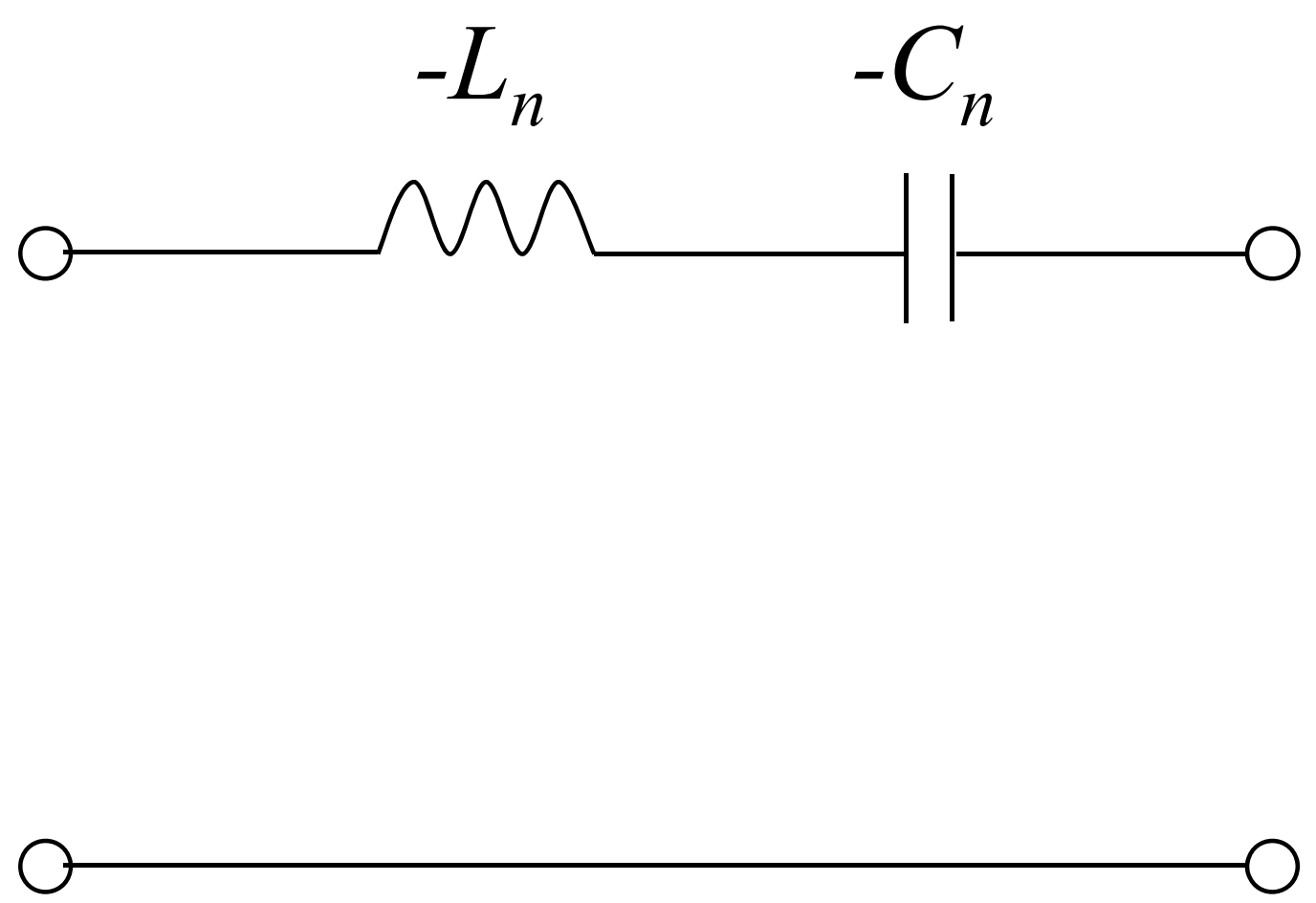
TABLE II

FReQUENCY RANGE IN USE IN THE PRESENCE OF VSWR CONSTRAINT

\begin{tabular}{|c|c|c|c|}
\hline \multirow{2}{*}{$\begin{array}{c}\text { VSWR } \\
\text { constraint }\end{array}$} & \multicolumn{3}{|c|}{ Frequency Range (GHz) } \\
\cline { 2 - 4 } & $\begin{array}{c}\text { Without } \\
\text { Matching }\end{array}$ & $\begin{array}{c}\text { Broadband } \\
\text { Matching }\end{array}$ & $\begin{array}{c}\text { Non- } \\
\text { Foster } \\
\text { Matching }\end{array}$ \\
\hline $\begin{array}{c}\text { Unconstraine } \\
\mathrm{d}\end{array}$ & $0.80-1.20$ & $0.80-1.20$ & $0.80-1.20$ \\
\hline VSWR $<3$ & $0.92-1.09$ & $0.84-1.14$ & $0.80-1.20$ \\
\hline VSWR $<2$ & $0.95-1.04$ & $0.88-1.11$ & $0.80-1.11$ \\
\hline
\end{tabular}


Fig. 9. Shannon capacity versus power delivery with a constraint of VSWR $<2$.

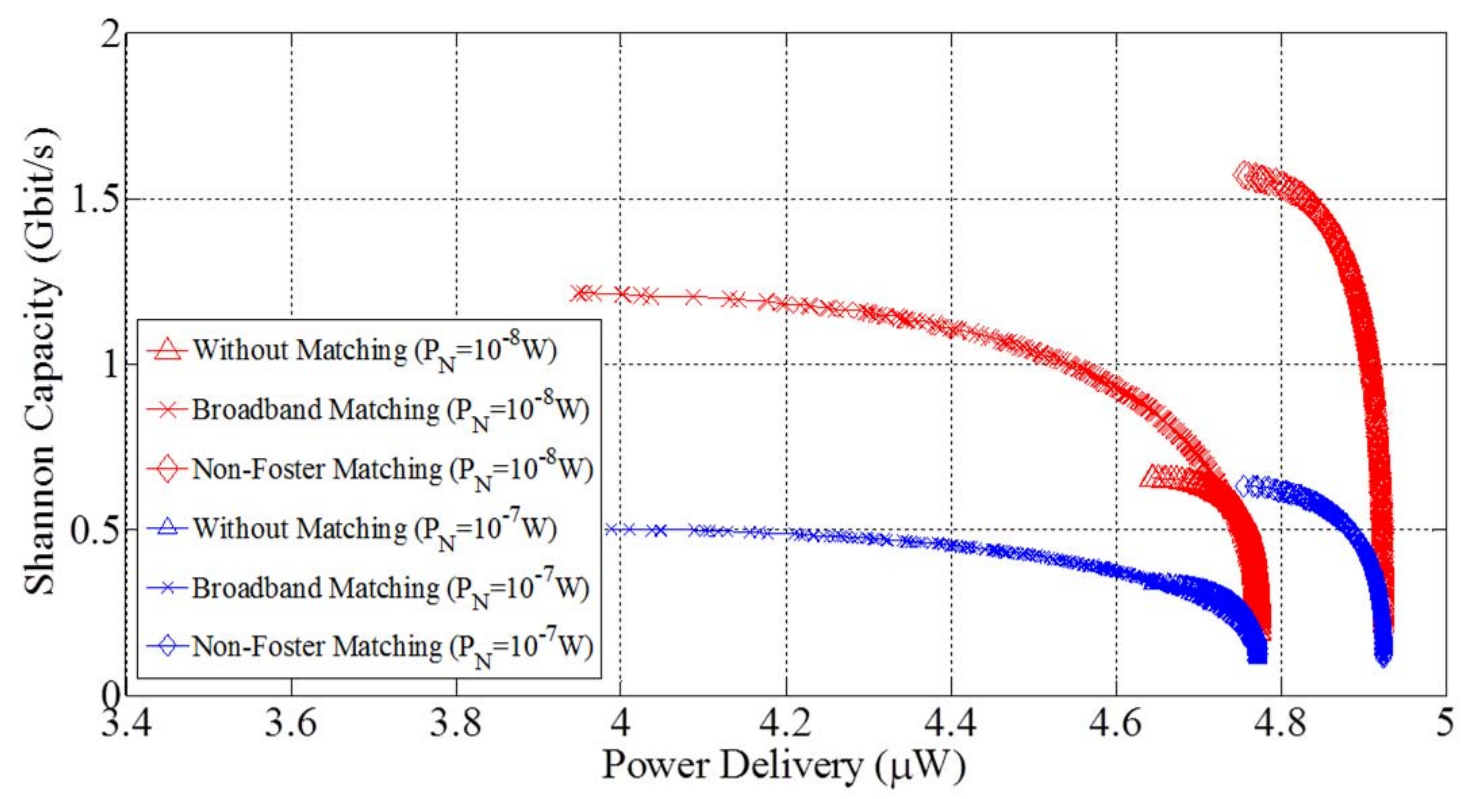


Fig. 10. Gabor capacity versus power delivery with a constraint of VSWR $<2$.

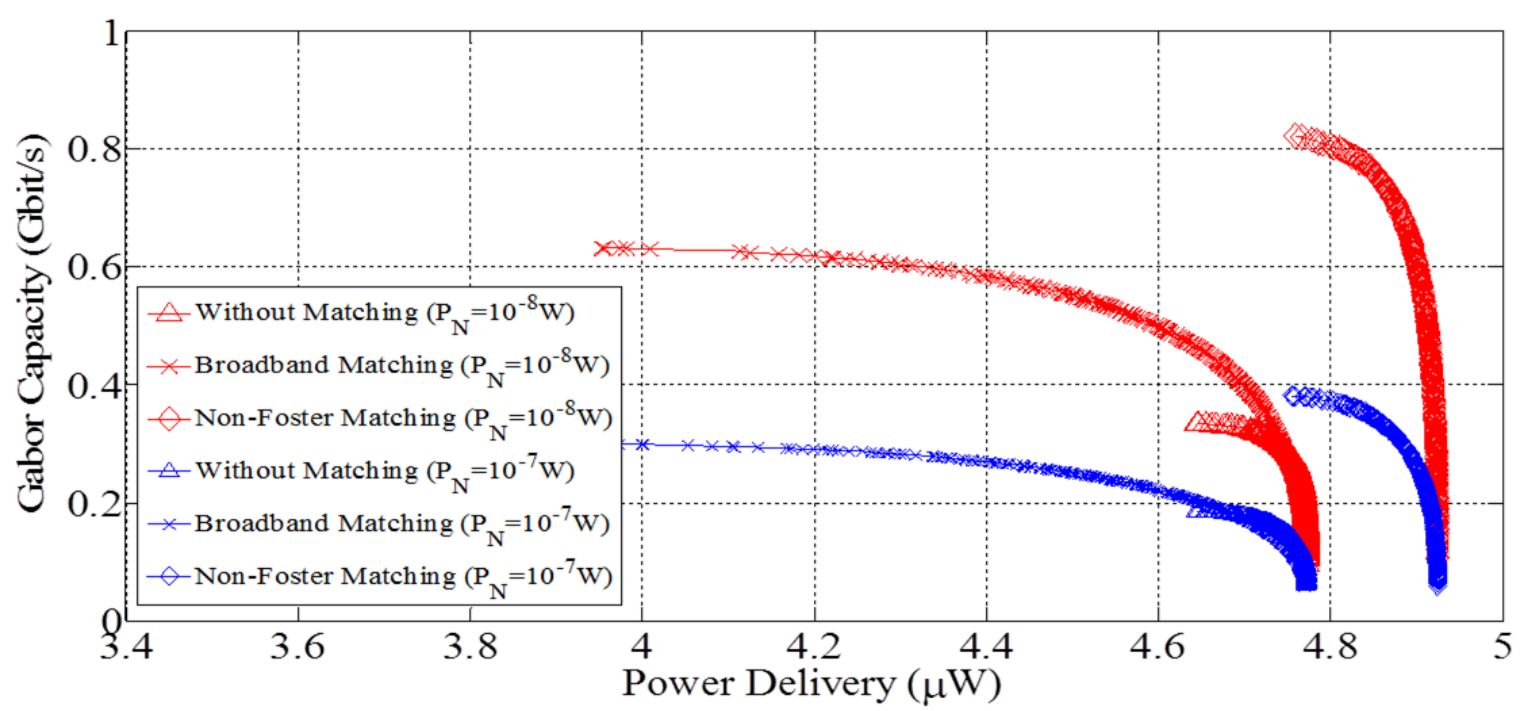


Fig. 11. HNT capacity versus power delivery with a constraint of VSWR $<2$.

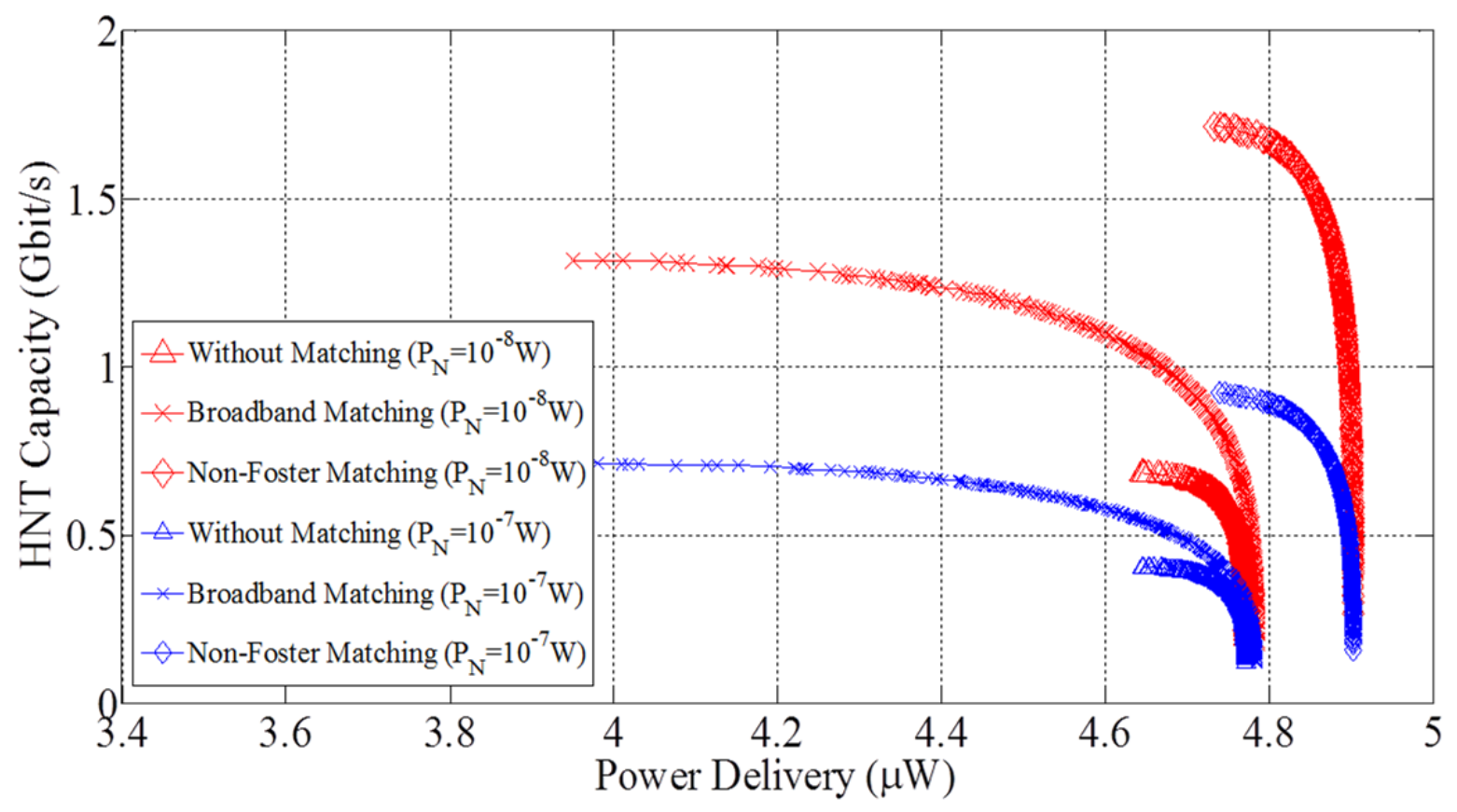


Fig. 12. Shannon capacity versus power delivery with a constraint of VSWR $<3$.

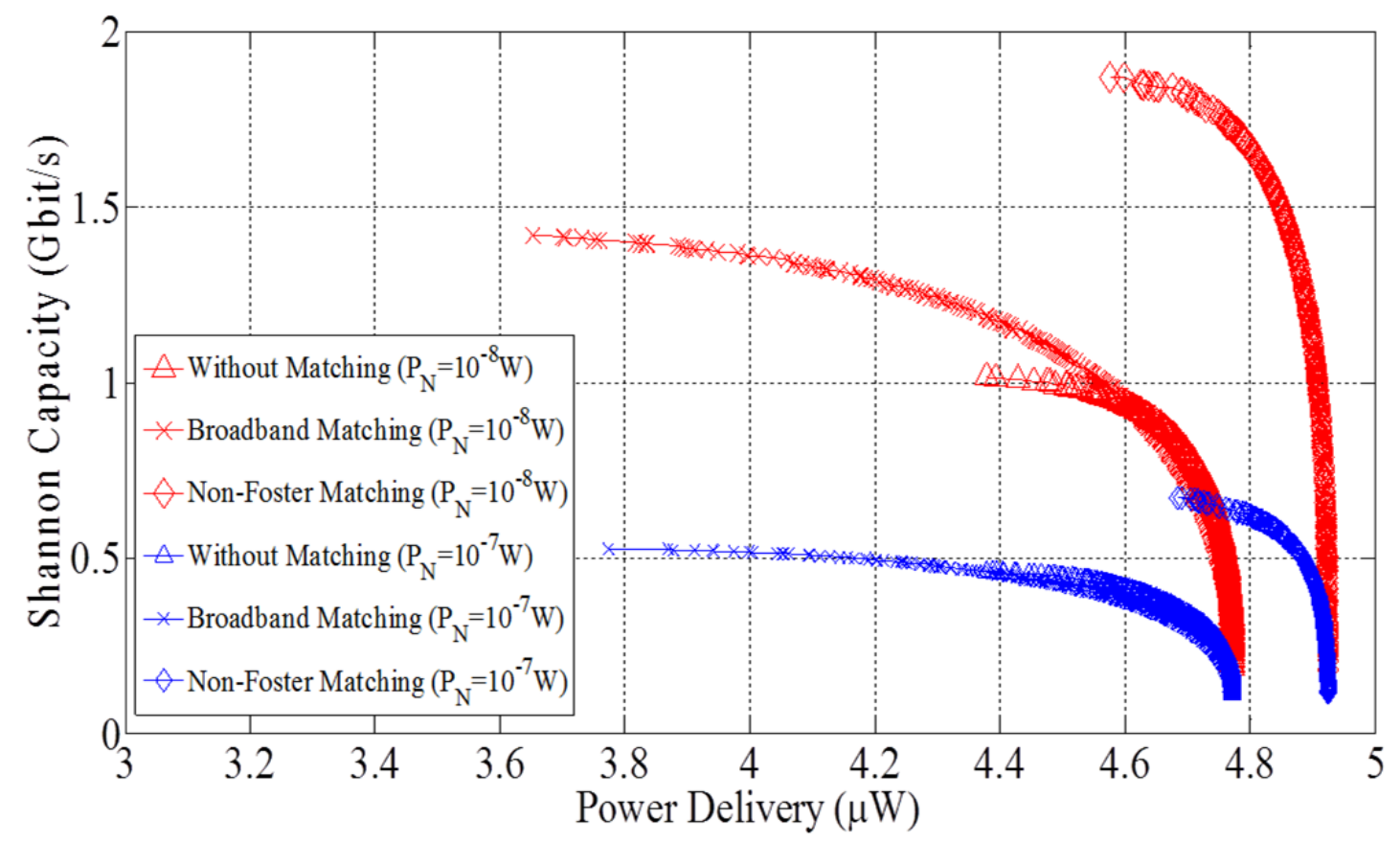


Fig. 13. Gabor capacity versus power delivery with a constraint of VSWR $<3$.

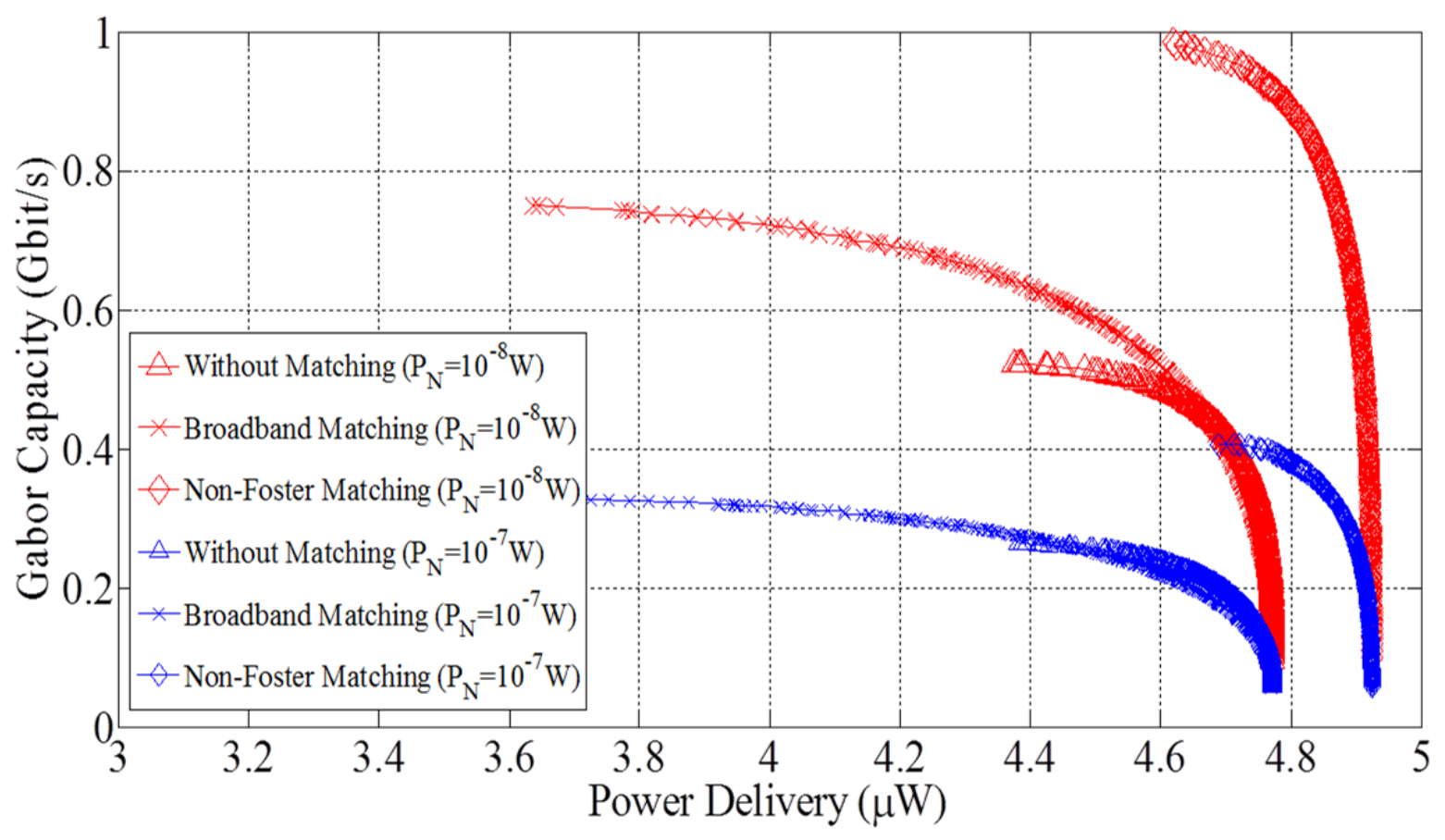


Fig. 14. HNT capacity versus power delivery with a constraint of VSWR $<3$

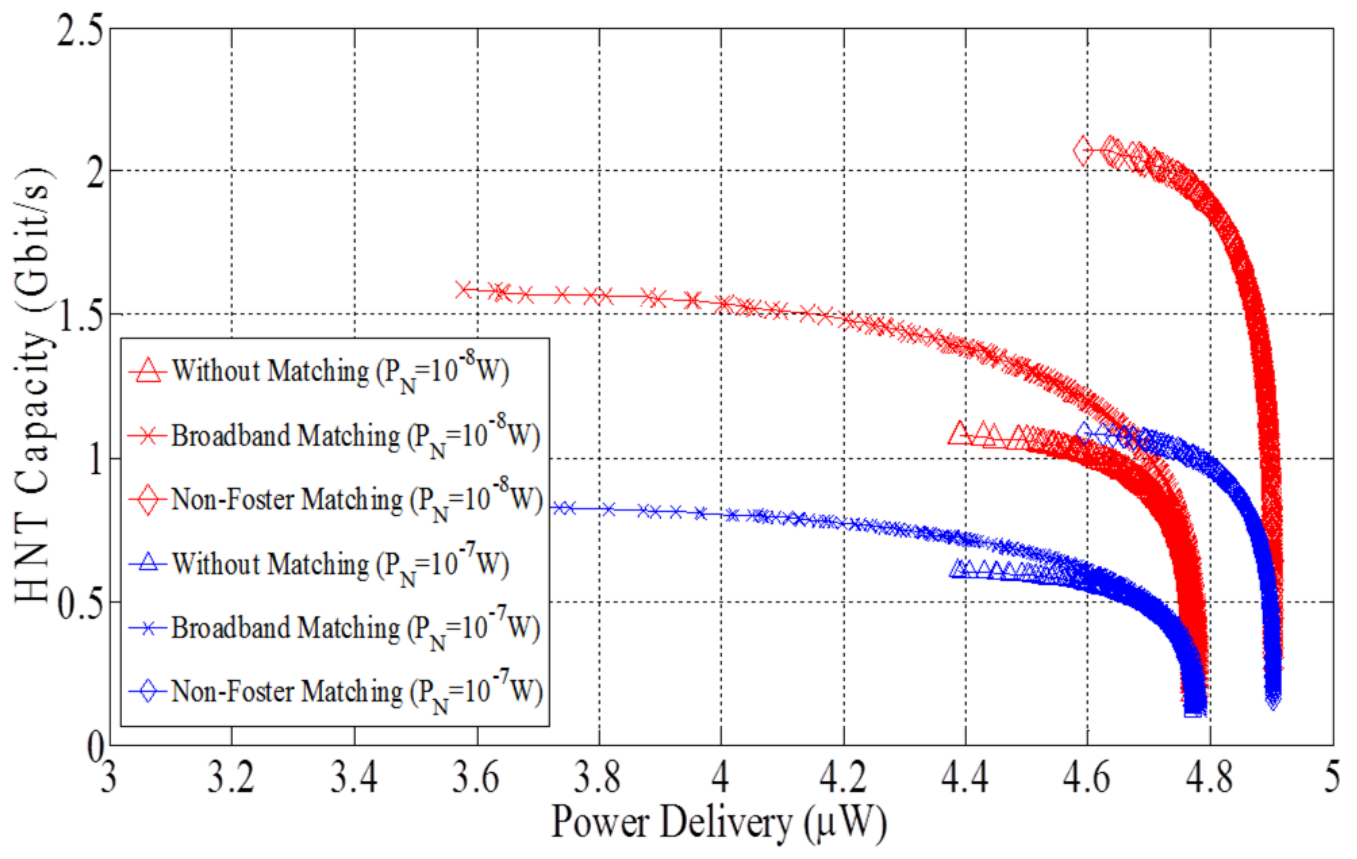


Fig. 15. Shannon capacity versus power delivery without constraint on VSWR.

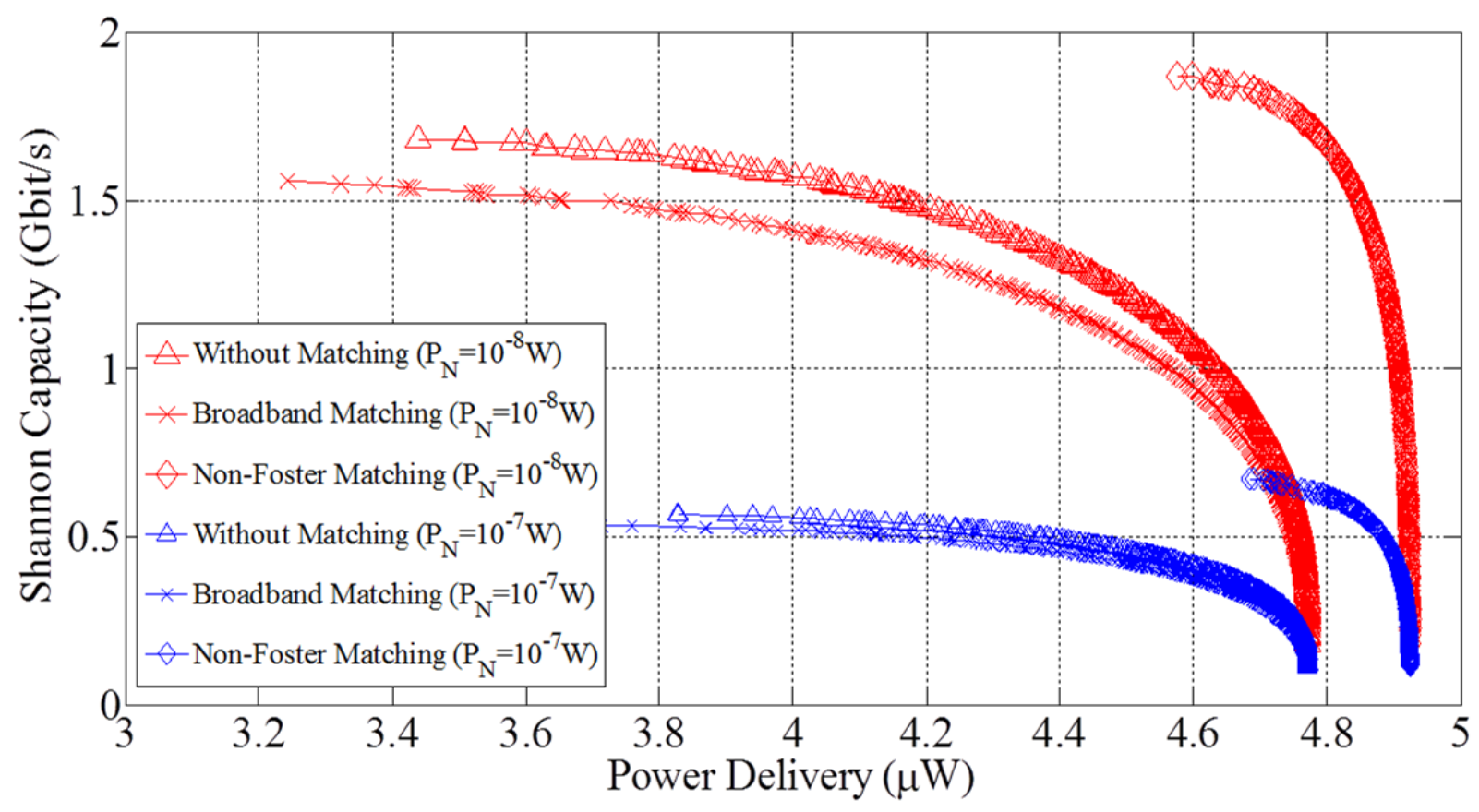


Fig. 16. Gabor capacity versus power delivery without constraint on VSWR.

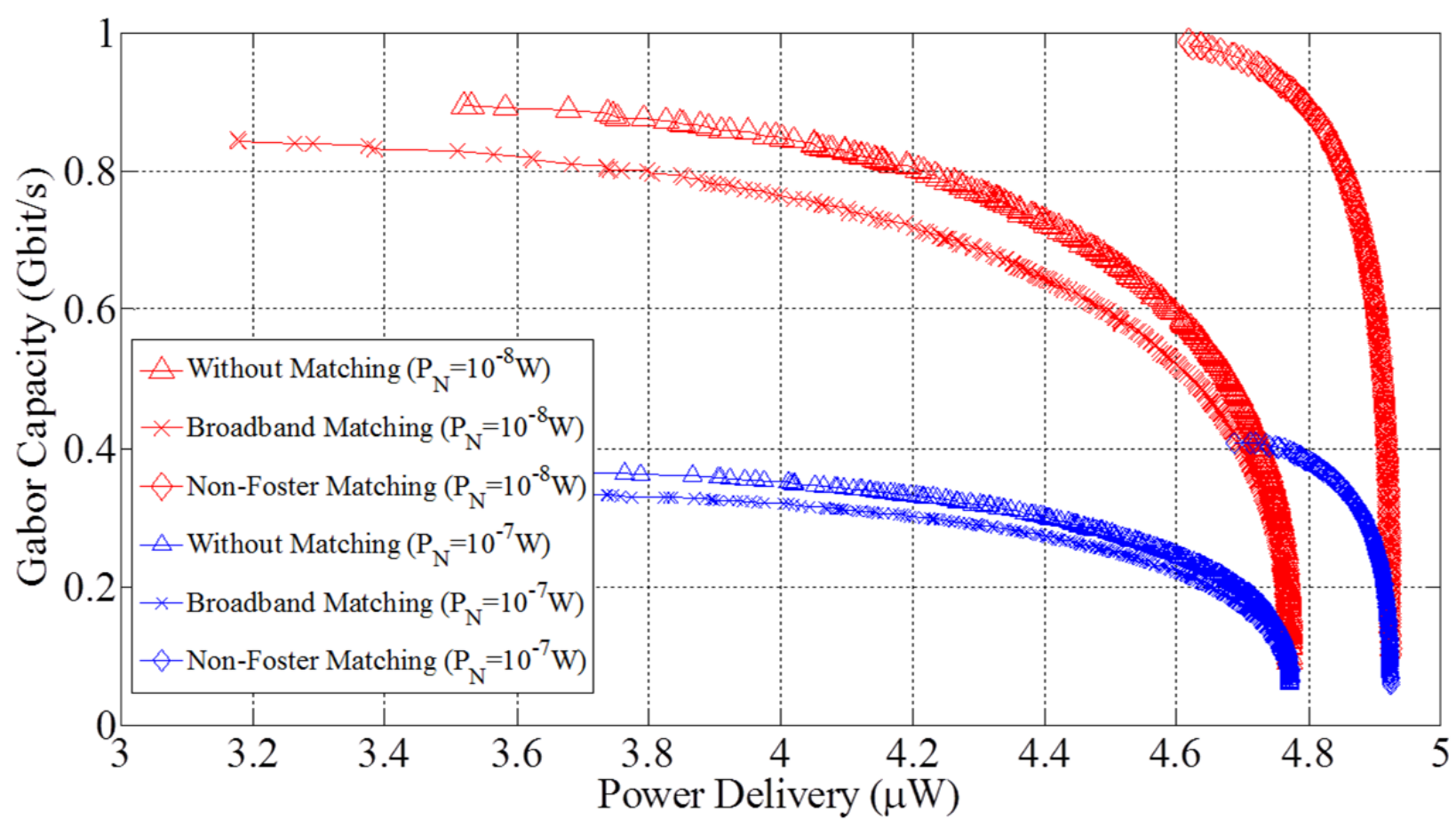


Fig. 17. HNT capacity versus power delivery without constraint on VSWR.

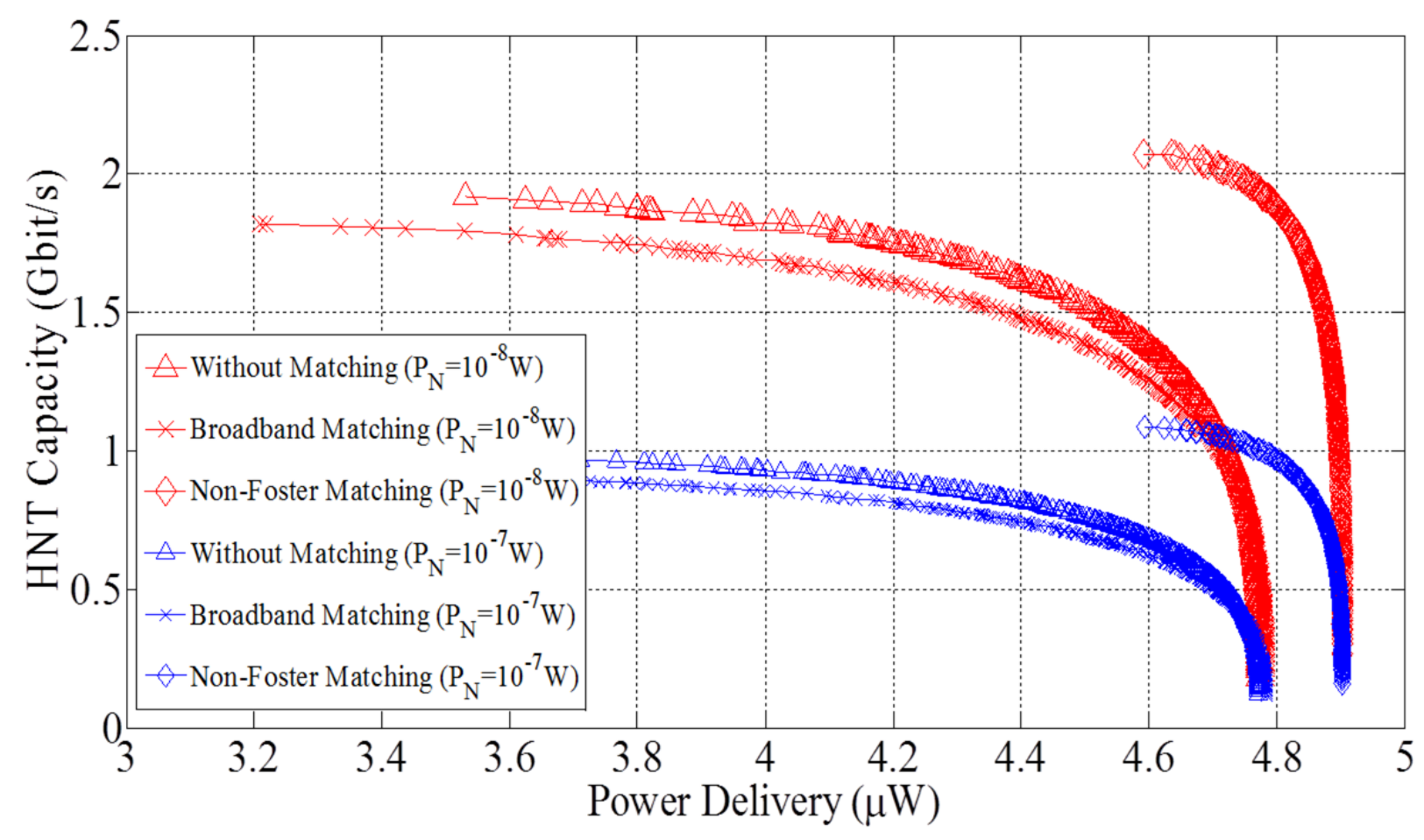


